\title{
High speed internet development in Africa using 4G-LTE technology-a review
}

\author{
Mohamed Njikam ${ }^{1}$, Nanna S. ${ }^{2}$, Shahrin S. ${ }^{3}$, Mohd Fairuz Iskandar Othman ${ }^{4}$ \\ ${ }^{1,3,4}$ Department of Computer Systems and Communication, Universiti Teknikal Malaysia Melaka (UTeM), Malaysia \\ ${ }^{2}$ Department of Software Engineering, Universiti Teknikal Malaysia Melaka (UTeM), Malaysia
}

\begin{tabular}{l} 
Article Info \\
\hline Article history: \\
Received Sep 1, 2017 \\
Revised Jan 10, 2018 \\
Accepted Jan 26, 2019 \\
\hline
\end{tabular}

Keywords:

4G-LITE

4G-LTE

Africa

Least developing countries

Voice over LTE

\begin{abstract}
The African continent is ranked second most populated region and has a huge amount of natural resources to be locally transformed or outsourced overseas. The traditional telecommunications system has helped connect people and enabled them to manage their businesses and trading in Africa for a long-time; many African countries have embarked early in changing their network and technology systems during the first years of the information age. Over a few decades ago, the introduction of new telecommunication methods and techniques have influenced much of African countries' growth via different perspectives. The situation has triggered an enormous interest in people. They analyzed the factors supporting such changes, which in the case of this paper is all about the advent and adoption of LTE/4G-LTE technologies including its service commercialization in Africa. This review article attempts to provide an overview of 4G-LTE networks technologies and the internet; it includes the current evolution of telecommunication networks within and even beyond the African continent, assisted by the 4G-LTE expansion. An extended view is provided throughout this article's development with respect to what could be expected (or is missing) for the sake of this continent's telecommunication infrastructure enhancement and a better QoS to Africa's dwellers.
\end{abstract}

Copyright $@ 2019$ Institute of Advanced Engineering and Science. All rights reserved.

\section{Corresponding Author:}

Mohamed Njikam,

Department of Computer Systems and Communication,

Universiti Teknikal Malaysia Melaka,

Hang Tuah Jaya, 76100 Durian Tunggal, Melaka, Malaysia.

Email: mohamed1nj@gmail.com

\section{INTRODUCTION}

A focus on the $4 \mathrm{G}-\mathrm{LTE}$ technologies and their features is the main concern of this section.

\subsection{Brief overview on $4 \mathrm{G} / \mathrm{LTE}$}

To define '4G/4G-LTE' (Say: 4G-LTE/ 4G-LTE/4G \& LTE) requires first to define and explain about LTE. And then, will follow a summary on its standards and features as tools enabling the global internet development. " $4 \mathrm{G}$ " is defined as the "Fourth generation of telecoms technologies". LTE stands for Long-Term Evolution and classified as a standard for wireless communication of high-speed data for mobile phones and data terminals [1-2]. And it is owned by ETSI (European Telecommunications Standards Institute). In various sources, LTE is introduced as the technology that triggered the implementation of $4 \mathrm{G}$ standard when it was still in the design progress under 3GPP consortium committee. On the business ground, LTE has been initially advertised as 4G-LTE, with ' $4 \mathrm{G}$ ' referring to the fourth generation of wireless technologies enabled. But, by that time 3GPP (3rd Generation Partnership Project) has not yet concluded on the contents for ' $4 \mathrm{G}$ ' standard requirement and its release, but later [1]. However, LTE owns great features for voice application and has earned much trust from industry with VoLTE as standard. Hence, '4G-LTE' 
and 'VoLTE' are gradually a realty in various research topics. As this background is going on (beyond this summary) one can see from other related sources that LTE triggered ' $4 \mathrm{G}$ ' birth.

\section{2. "4G/LITE" basic appealing features}

LTE is a multiple frequencies and bands enabled technology whose design is so intended to match with the locally affordable provisions of interest within every host land. This deployment's polyvalence is provided for easy adaptation with the local network facility throughout the world. It is an impressing feature for multi-band phone's holders connecting easily with LTE service in their visiting countries. Therefore, '4G-LTE' introduction in African countries offers such double edge to their visitors to remain connected using a single handset. Moreover, 4G-LTE projects targets are to increase wireless data networks' capacity and speed, to change/reduce the network architecture levels to only IP-based system, to keep existing $2 \mathrm{G} \&$ 3G operation beside LTE wireless interface; etc.; [1], [3-4]. Now, relatively to good environmental and politics issues about systems setting up, Africa offers greater hopes for LTE growth and development compared to its initial host land of performance test [5-6].

\subsection{Special features for 4G-LTE users}

A lot is written about 4G/LTE tremendous advantages, with various highlights from different literature sources. For instance [1] listed voce calls and voice over LTE (VoLTE) as special provisions for 4G-LTE users. Voice quality is one of the greatest stimulating features behind market boom of new technologies for telecommunications and networks commercial products. This includes supports for communications business services. These details have counted as motivation for the former network investors prior to 4G-LTE network deployments in Africa, including the reuse of legacy system is among its "top" features [1], [4], [6-7]. However, Africa is unique among continents with more than 95\% countries set together on firm lands, and thus easily possessing wired telephony networks -a strong legacy. Therefore, whatever would be the QoS offered by the future networks' generation, the actual challenge for performance quality will be about meeting much closely the QoS model experienced and provided by land-based phone calls and data transfer performance. Thus, only networks with features-based comfort enhancers can create the real difference to users; and 4G/LTE is of such category and can undoubtedly capture people attention and then easily stimulate users' liking for its acceptance.

VoLTE or wired network legacy reuse enabled in 4G-LTE is a sort of transferring path of a voice call from LTE system into a called Circuit-switched fallback (CSFB) set at the back-gate of the system for such transfer purpose. Thus, LITE only holds the data services to be handed over a circuit-switched domain once a call is signaled.

\section{2. “4G-LTE” DEVELOPMENT IN AFRICA}

The section introduces 4G-LTE expansion in African countries, then, it discusses how far those countries have taken advantage of this cohabitation to upgrade and develop of their networks' system.

\subsection{Internet Development with 4G-LTE Advent}

Here, sample data about communication technology per countries showed important projects of internet extension. Among recent sources, [8] reported various efforts at government levels, supported by local or foreign investors. In this continent ranked second largest world's populations, 4G-LTE actually has more potential to contribute in both communications facilities' improvement and nations' economy development. As shown in Figure 1, compared to the other world's continents, Africa is still the only region offering more entries to service providers/network deployments, including business operators using LTE.

This paper's Section 3 introduces 4G-LTE project objectives, which addressed much for developing countries' networks development. And, undoubtedly 4G-LTE systems can help turn into reality and make it then happen with the required changes for the improvements of developing countries' networks worldwide. Despite the limitation in data, the end of this paper (Section 5) attempts providing a comparative result on the internet growth, its consumption and deployment around the world; with a focus on the status of African countries.

African countries are special case for having participated/been involved into various technologies development as test-bed [1,9]. However, there are some important questions that one would like to ask on this expansion over there. One of the most crucial ones is about the extent to which those nations have managed/are managing to take advantage of $4 \mathrm{G} / \mathrm{LTE}$ to improve their own systems. And then, how such arrangements are/can be embedded into a real process for the nation's growth. Many efforts have been/are deployed by foreign partners in expertise transfer and managers training to help [9] or promote the nation's growth [10]. In fact, rather than only to serve the foreign party using the nation (people /or their lands) merely for the sake of good communication services they are offering [9], [11-15], it is important also to 
think about the host country's economic and social developments as well. This issue requires more commitments from local and foreign parties; local government's decisions, policy and regulatory approaches, which are mainly such parameters to play the missing key-roles [9], [13-14], [16]. Thus, technologies exporter's philosophy, local politics and policy regarding the networks markets/projects' offer and conditions for potential operators are the right tools manageable to hopefully resolve many of these introduced problem [9], [11-15].

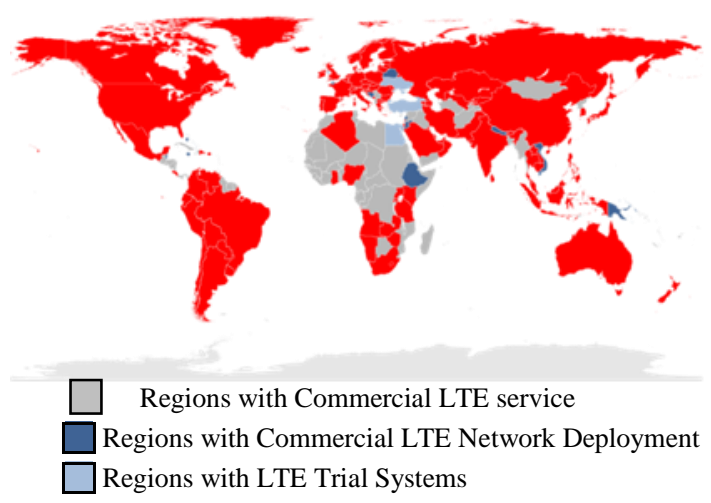

Figure 1. 4G-LTE Penetration in Africa, ITU 2014 [1]

\subsection{LTE penetration in Africa vs local project}

Here is some sample information showing that 4G/LTE entry and contribution can do a lot there. This is based on [3]'s critical analysis about how ICTs deployment is tackled to enable access to crucial services-selected examples from the 54 African countries:

a. Zambia to transform learning through interactive ICT (iSchool).

b. South Africa Republic in broadband for everyone to deliver broadband to underserved areas.

c. Nigeria and Senegal, to integrate mobile technologies into teacher development through Nokia cooperation motivated by UNESCO.

\section{3. “4G-LTE" AND FOREIGN CONTRIBUTION INTO INTERNET DEVELOPMENT IN AFRICAN COUNTRIES}

Research information and other historical facts featuring on African Internet progress are still not much accessible due perhaps to limited openness for shared information on the ongoing process with networks' technology's suppliers [8-9]. However, to this point, many African nations' representatives provide only a quick update about how far and how much they are engaged with technology arena [8]. But, such lack of common ground of discussions has landed a type of discrepancy in the projects realization, even when they are handled by a same network industry or company within sub-region's countries cannot just build up a nearly same policy to make the deal better run [9]. Hence, the traditional internet infrastructures suffer somehow from the absence of strong consideration for the global policy recommendations about broadband and related $[3,9]$.

Some constructive ideas are proposed as solutions by foreign partners using similar facts between all countries worldwide. Anyhow, the selected points stated here are expected easily manageable based on African leaders who are preaching regionalism identity pact for a union since more than a decade ago through African Union (https://en.wikipedia.org/wiki/African Union). According to [9], specific steps to achieve expanded cross-border connectivity project include: (a) ongoing/ fostering regional partnerships (e.g. ease for licensing \& construction permits); (b) encourage infrastructure sharing (i.e. support to new entrants); (c) seek input from the private sector (i.e. Negotiate assistance from experienced investors); etc. Thus, 4G / 4G-LTE presence is considered as a real panacea for various unstated and hidden issues about networks development in African countries

The top cases reported in telecoms magazines and blogs are based in majority in Africa sub-Saharan countries -e.g. Ghana, Cameroon, South Africa Republic, Senegal, Zambia, Nigeria, Uganda, Zimbabwe; etc. Referring to [17] recent report based on a study conducted by one of the top mobile network operators in Africa sub-Sahara, their contributions are salutary at all levels. Their commitments in deploying and commercializing LTE/4G-LTE services have raised African countries to rank the world's third-largest mobile subscriber market, behind Asia Pacific \& Europe; to support sub-Saharan region and to offer more with some 
very high achievements forecasted for 2020. A contrasting point to these details is regarding the cost to pay, reading from [9]:

"Improvements in infrastructure alone do not always result in lower prices or improved quality of service for end-users... an enabling environment is an essential component to bridging the digital divide and bringing about the benefits of connectivity to developing countries" (Tunis Agenda for the Information Society [9])".

And similarly [10] and [18] instead discussed some ways after questioning: "How to make the middle classes enter the digital age?" These two among other rhetoric views can have different explanations: earlier introduced difficulties (e.g. Taxes \& license fees, labor cost) faced by operators from local governments, including the global economy influences. Some further discussions on these points are out of this paper's scope.

\section{TRADES OPPORTUNITY WITH 4G-LTE IN THE CONTINENT OF AFRICA}

Figure 1 clearly shows that 4G-LTE got/has more activity spaces in African counties than in elsewhere continent's nations; thus more opportunities: for LTE can be its technology further testing and development; whereas for local countries hosting LTE deployment, both learning and taking advantage to develop specific products of citizen's interest and mainly the vulgarization of the Internet to reach remotely located people from main big cities/urban areas. Unfortunately, this is not always possible as discussed in [2], [7], [9-10], [16-18] due to either the local government policy or inadequate follow up/lack of rational implementation of contract.

Many writers have given to this continent various qualifiers and attributes. Most of them describing it as the unique world's land richer than any one elsewhere with almost everything 'for everyone'. And yet, [2] described it as: "Africa: a continent offering a world of opportunity". Here are other kind words about Africa's offers to the rest of the world: "Africa among the most innovative, world testing lab, a leader in mobile applications [2]; and recently 2017/2018: the global telecommunications 'SAIL' (South Atlantic Interlink) host via Kribi/Cameroon [16].

Referring to business and trades opportunities linked to the internet development, there are/will many through 4G/LTE use. But, there must be some powerful performance networks to minimize the needs for maintenance and assurance costs and to increase user's satisfaction [2]. This dream has become reality with the deployment and commercialization of 3G / 4G-LTE respectively in $41 \& 23$ of the 54 African countries [17].

\subsection{Projects missing steps in managing opportunities with 4G-LTE}

In careful planning to welcome 4G-LTE and parodying Shailabh Atal, Mohamed Kande and Harish Nalinakshan in [2], "one can say: strategically, host country's government and operators could have taken advantage of their networks stock and invest first in improving and upgrading their existing networks while planning for embarking onto new technologies negotiation. For, telecommunications' legacy still has sufficient facilities /infrastructures needed by 4G-LTE to get quickly started with internet connections extension. Thus, this way could offer them good time to find out their limitations and needs, prior to their rollout in full [2], [9], [17]. Such a procedure could minimize drawbacks such as high costs and required time for debating agreements [7], [17-18].

The above statements mean that 4G-LTE technologies have come to Africa for purely the sake of Internet. However, they will hardly achieve economic and social developments of the host countries without proper ruling on their entry's contract by the nation's government, but relying only o investment agreed taxes [2], [10]. Failure of seriously doing so led Africans cases (i.e. Internet users' lowest rates) in Figures 1-3, with Africa being the world's best lab testing of latest telecoms technologies [3], [14-15].

Referring to standards definition, 4G-LTE is the telecommunications technology model suitable for all third world/developing countries (DC) whose top of features is the ability to provide users with both data and voice. However, while DC people have to face the services supply charges, yet, very few citizens are up to affording it including mobile handset's cost. Hence, between local or foreign parties on project's policy discussion, one of the very missing elements is about a poor fix in everything with rules/regulation/policy applied on the operators as [1], [2], [7], [9]; and others along with taxes charges disclosure [9], [17-19]. 


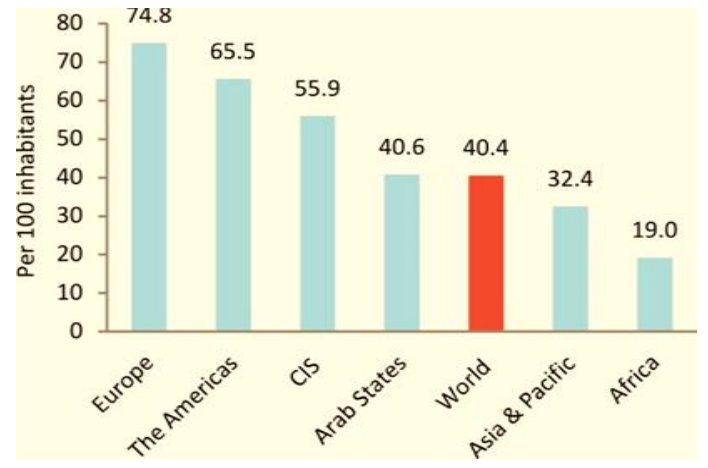

Figure 2. World's individuals using the internet [3]

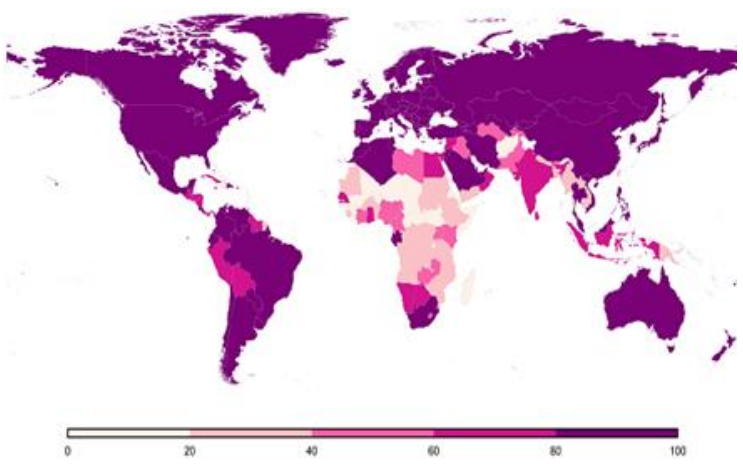

Figure 3. World's estimate proportion of youth (15-24-year-old) internet users, 2017

(Source; ITU) [16]

In fact, countries which have succeeded in network development deals have experienced also most of these issues and got rid of them through their nation's IDA (Information Development Authority) commitments wherever required. Therefore, it is believable that a good provision of laws along with adequate IDA body committed into their follow up can be the way out with all above issues. For, every nation's regulatory IDA can legislate to protect the country and its consumer's rights while ensuring that SPs are not much like being penalized by laws/policymakers; countries fairly succeeding with IDA are introduced in [9], [11-15], [20-21].

\section{FACTS FOR INTERNET DEVELOPMENT IN AFRICA WITH 4G-LTE}

An analysis of 4G/LTE/4G-LTE features definition shows that there are sufficient ways along with these new technologies for African countries' internet existing systems' faster enhancement [1], [3], [8], [18], [22-23]. And most of genuine facts are based on ITU (international Telecommunications Union) 2014 global survey and other studies reported in [9], [15], [18], [22-23].

Based on report's findings in Figure 2, a comment stated that the value of comparing African ICT benchmarks with global states is marginal since nearly all African nations perform below average in terms of ICT access, use and with specially consumer's unaffordability to network deployment cost and services price [3].

In fact, some unanswerable questions can be raised. For instance, what explains such above details when considering all attributes assigned earlier (Section 4) to African continent-countries positive response to telecommunication technologies and services providers, hospitality to foreign engineering and technical research and projects testing.

An amazing fact is what happens after giving training to people; then they are still not bringing up the change when implementing the acquired knowledge. Probably there is a slow follow up and little dynamic cooperation with the "masters" throughout projects implementation [10]. Thus, consequently the QoS which is not only for the services and its good delivery but all about consumer's rights are looked down. Illustrations include the analysis about such issues in Ghana by Franklin Cudjoe (2015) [24] and on the world 2016's survey statistics [16].

Figure 3 easily displays that Africa contains countries (e.g. Congo R.D, Eritrea, Niger) with the lowest internet user rates by youths, few (e.g. Tunisia, South Africa Republic, Egypt) rank among top users [15-16], and therefore it remains the biggest technology trades' offer for both 3G LTE and 4G-LTE.

However, based on world 2017's survey, the internet user's highest rate (94\%) goes to advanced countries; then $67 \%$ and $30 \%$ respectively for DCs and LDCs. But, with several hundred million youths using the the internet, "nearly 9 out of 10 who do not use the Internet live either in Africa or in Asia and the Pacific" [16]. Thus, with respect to Africa particular case, LTE has come closer and obviously only some more proper commitments between involved parties in related projects are needed in order to deliver the expected changes in developing telecommunication networks at domestic and global levels.

The most obvious interpretation to the findings (Figure 4) for less and developing countries can be traced back to the availability of network access point (e.g. Cybercafés, school/university's Lab/libraries, homes \& offices), including the costs for services use or for deployments as the most common barriers (Figure 5). And this is expressed in [15] article in the name of influence of regional diversity (i.e. Language, economy, cultures and others). It is interesting to notice that the observed change has taken place as a result 
of the few years of 3G and mainly 4G-LTE's deployment around all listed countries, despite the various difficulties or issues discussed in earlier sections of this paper.

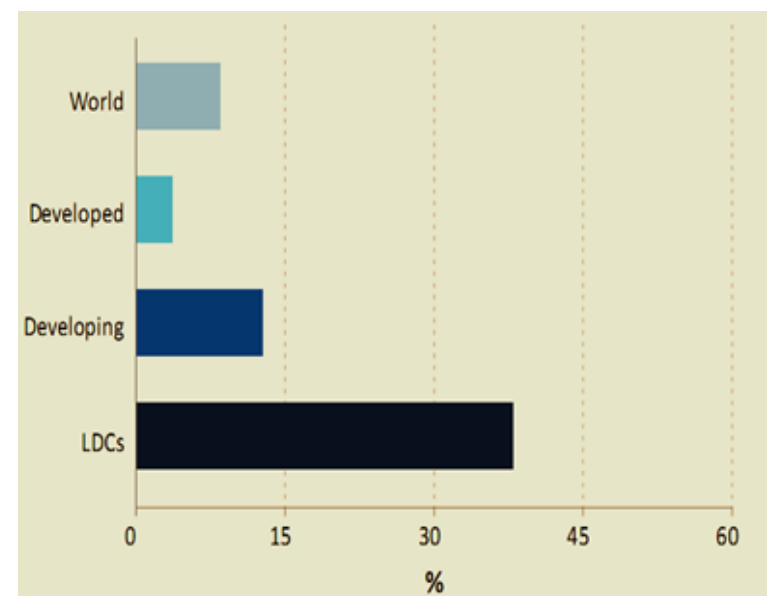

Figure 4. World's internet subscriber penetration (Source: ITU) [16]

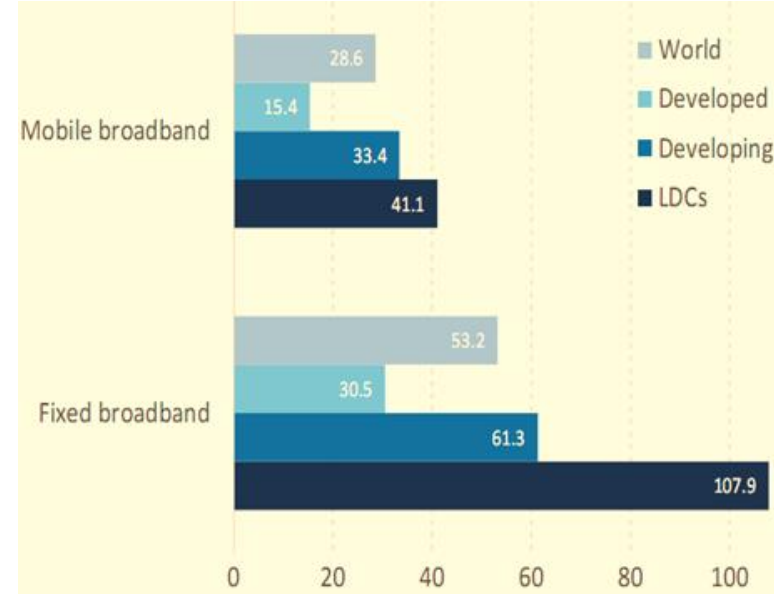

Figure 5. Fixed vs. mobile broadband deployment and services pricing (2016) as challenging barriers to the Internet access (Source: ITU) [16]

The [15]'s survey paper articles remarkably stress the discussions about selected top African countries, which have experienced growth in internet use (2001 to 2007, albeit at different rates over few year intervals. In contrast, such observed rate change is still among the lowest around the world almost 10 years after.

\subsection{Pricing challenge as barrier to internet access}

Initially that many least developing countries (LDC) and developing countries (DC) especially in Africa are luckiest for living on fully firm lands with the vast majority in prosperous region with also very good pluviometry/rains falls (favoring then for poles farming used in Telephony and electricity cables distribution). Generally speaking and as local resources, they are supposed to fairly enable lowering the costs of the new technology distribution; and perhaps making it cheaper when relying instead more on using the air (wireless).

An interpretation of data in Figure 5 shows in contrast an opposite; i.e. simply, fixed broadband is both difficult in subscription (Deployment) and more expensive (2.6 times more) than broadband counterpart [16], while mobile broadband offers charge chipper cost for either deployments or services delivered to users [10], [16], [24]. Some sufficient discussions from survey and other studies believe in their analysis that particularly every DC/LDC's government has the rights and power to help improve /change the situation [1], [3], [8], [18], [22-23]. For, governments can agree by consensus through individual IDA-(nation) Information Directory Administration, to especially ensure that citizens are delivered fair services quality, while domestic and foreign networks operators' growth make also significant impacts on the county's social and economic developments.

Most of the major/common networking communications development problems for great Internet development if Africa can be achieved with respect to LTE technology fundamental aims and available services packages [1], [11-12], [23], [25-26]. Moreover, already existing network and services provisioning in many African countries [16-17] are such promising proves that there are various possibilities to grab and enable the implementation and development of the Internet and services quality between and beyond African nations. In fact, issues such as facility installations and services pricing [27] are among other matters discussed in [13], [24] materials that can be solved over time restore fairness wherever it is missing. The situation (Figure 6) shows roughly that DC and LDC nation's people are likely paying more to/for the networks/internet providers. Nevertheless, no one best knows why and how but obviously those country's governments, which are the supreme authority from where can be initiated and bridged any ideas for change processes to such problems. 


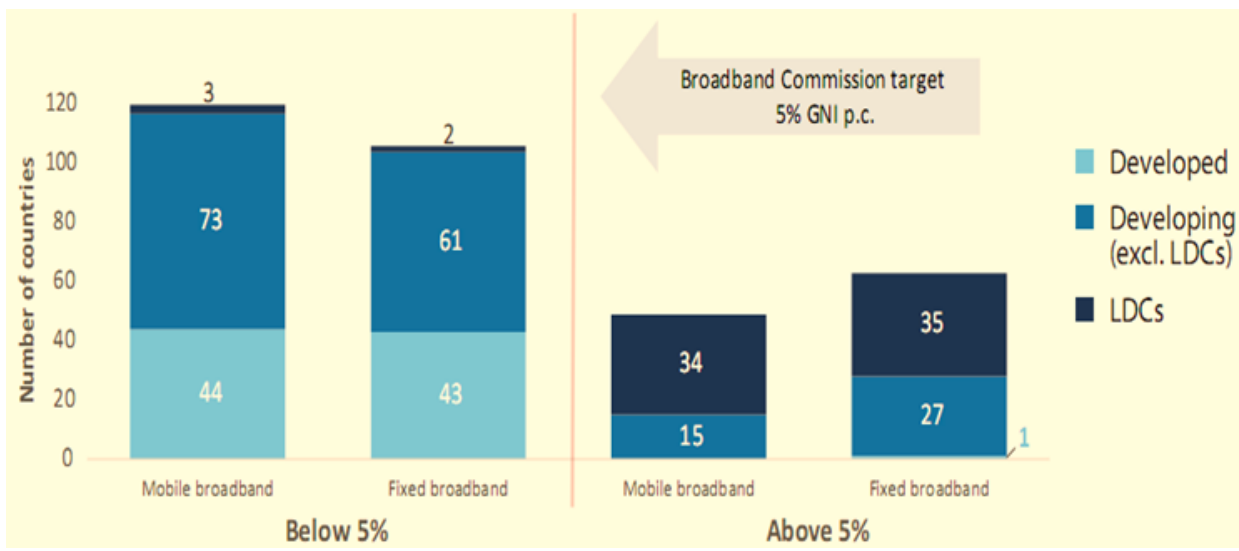

Figure 6. Broadband prices as barrier to the Internet access

African countries are tackling more tremendous Telecom projects like SAIL (South Atlantic Inter-links) for Brazil, via Cameroon Telecoms (CAMTEL) services; it is to bridge the world digitally and economically to boost exchanges between continents through African continent this way and others [15]. According to Gary Maidment [15], this project leader said that nothing is needed much for such a realization to take place, but only/mainly "the right mindset, strategies and technologies" - i.e. obviously the missing elements about other data networks projects presented in [11-12], [17], [23], [28]. Indeed, a particular concern with such great projects is that among operator's accomplishments over time, they must contribute to the host country actual development rather than keep using people lands/environments merely as testbed for what will benefit more or even only foreigners in developed nations.

\section{CONCLUSION}

This paper has gone through some available academic materials and important facts as in communication journals and technical reports on the African continent and specific countries. However, 4G-LTE and the internet constitute an important topic, which cannot be discussed only locally. By the way, few reviewed surveys-based articles have provided this report with a better picture of this topic in the case of African countries. For instance, the investigation/exploration of mind-set and the spirit of network operators and governments in prospects, and how they usually go about building local capabilities and creating new networks for new markets-that is the typical content attempted in coverage throughout this document.

Nevertheless, 4G/LTE networks QoS in Africa, is almost a winning case despite all witnessed weaker points related to the rights of the consumers. Moreover, the highlighted issues are merely a reminder on the case of African countries like occurred elsewhere before or currently. Therefore, to the conditions with 4G-LTE internet development in Africa, they obviously need people with good moral and concerns for others in their doings, can they be from local or foreign parties. Therefore, as the opportunities to harvest are just huge for both African dwellers and foreigners, there should be some suitable solutions framework to take these advantages. The users' increasingly positive response to 4G-LTE's services and commercialization is a significant sign for its growth in Africa, though its rollout is suffering from some difficult conditions facing the operators.

Hopefully this review has presented fundamental highlights that can guide its readers to reach further details in other sources. And the information gathered here may be useful either for general knowledge on the topic or as inputs into typical research literature. A future work intends to utilize the AU sub-regions or grouped countries; then attempt to look into in-depth causes of both the networks/Internet and the country low development growth with respect to using the new technologies like LTE or 4G-LTE.

\section{ACKNOWLEDGEMENT}

We would like to acknowledge the financial support given by Universiti Teknikal Malaysia Melaka (UTeM), through short grant PJP/2018/FTMK(6B)/S01634. Our thanks and appreciation also go to the authors of all those materials we reviewed, which have contributed to this article. 


\section{REFERENCES}

[1] En.Wikipedia.Org/, n.d. LTE (Telecommunication); [http://en.wikipedia.org/wiki/LTE_(telecommunication)]

[2] Telecoms in Africa: innovating and inspiring Communications Review, A journal for telecom, cable, satellite and Internet executives, Volume 17, No. 1. (2012 PWC.

[3] O-Africa, Tim Katlic, 2015 African Highlights from 'State of Broadband 2014' Report, ITU/UNESCO--The State of Broadband 2014: Broadband for All, [http://www.oafrica.com/news/ the State of Broadband 2014/].

[4] O-Africa, 2012 Understanding Broadband Demand in Africa: Internet Going Mobile, Broadband \& Mobile, [http://www.oafrica.com/mobile/notes-from-understanding-broadband-demand-in-africa-internet-going-mobile/].

[5] NTT DOCOMO, 2010 Market DOCOMO Takes the Next Big Steps with LTE, DOCOMO Newsletter Mobility 31, Issues Dec 2010.

[6] NTT DOCOMO, 2012 LTE today \& tomorrow; DOCOMO Newsletter Mobility 35; Issues Jan 2012.

[7] Jon M. Peha, 2010 The Public Safety Nationwide Interoperable Broadband Network: A New Model for Capacity, Performance and Cost; FCC Whitepaper, Federal Communications Co 445 12th Street, SW Washington, DC 20554,

[8] O-Africa, Tim Katlic, 2014, Country-by-country African ICT highlights from 2014, Tracking Internet Progress, [http://www.oafrica.com/news/country-by-country-african-ict-highlights-from-2014/].

[9] Internetsociety.com, 2014 Internet Society Contribution (ISOC) to the 2014 ITU World Telecommunication Development Conference (WTDC), Whitepaper, Sixth World Telecommunication Development Conference (WTDC-14), [www.internetsociety.com].

[10] w3.isoc.org/, ENSP Julius Nashipu Roger Bello, 1997 Internet Development in Africa: The Case of Cameroon; Proceedings/E4/ENSP School of Polytechnic Yaoundé-Cameroon; retrieved:06-06-2017 from: [https://www.isoc.org/inet97/proceedings/E4/E4_1.HTM]

[11] BEREC, 2012 A view of traffic management and other practices resulting in restrictions to the open Internet in Europe, BEREC: Body of European Regulations for Electronic Communications; BEREC press BoR (12) 30.

[12] BEREC, 2012 Differentiation practices and related competition issues in the scope of net Neutrality; Final report, BEREC: Body of European Regulations for Electronic Communications; BEREC press BoR (12) 30.

[13] Ms. Lim Choon Sai, 2000 Concert Global Networks (Singapore) Infocomm Development Authority of Singapore, Direction (Regulation) Government \& Regulatory Affairs; (Comments on the Review of Quality of Service Framework for Broadband Access Services); Pte Ltd.

[14] Mr. Lim Choon Sai, 2000 Consultation Paper on Broadband QoS - Review of Quality of Service Framework for Broadband Access Services, Industry Consultation, Infocomm Development Authority of Singapore.

[15] Internetsociety.com, Towela Nyirenda-Jere \& Tesfaye Biru, 2014 Internet development and Internet governance in Africa.

[16] W3.itu.int/, Brahima Sanou, 2017 Facts and Figures - ITU, ICT Facts and Figures 2017, [https://www.itu.int/en/ituD/Statistics/Documents/facts/ICTFactsFigures2017.pdf]

[17] Balancingact-africa.com, 2015 Mobile Contribution to Sub-Saharan African Economy Surpasses US\$100 Billion, Finds New GSMA Study, Telecoms, Internet \& Broadband in Africa, Balancing Act, news-Issues \#798. Press Release 8, [http://www.balancingact-africa.com/news/en/issue-no-798/telecoms/mobile-contribution/en]. Copyright 2014 Balancing Act.

[18] Deloitte global M\&A presence, 2014 The future of Telecoms in Africa the "blueprint for the brave", Deloitte African footprint; Deloitte TMT - our global presence. (c) 2014 Deloitte \& Touche. All rights reserved. Member of Deloitte Touche Tohmatsu Limited; retrieve 17-02-16.

[19] BiztechAfrica, 2016 MTN Cameroon Board lauds 3G+, 4G-LTE rollouts Telecoms, Main Africa MTN Cameroon Board lauds 3G+, 4G-LTE rollouts, available at: [http://myinforms.com/en/a/24362364-mtn-cameroon-board-lauds$3 \mathrm{~g}-4 \mathrm{~g}$-lte-rollouts/]. (C) Biztechafrica.com.

[20] GSMA Europe Blog, 2014 Regulatory issues impacting 4G deployment, GSMA Europe Blog.

[21] W3.huawei.com, Gary Maidment, 2018 SAIL the Atlantic with CAMTEL - Huawei, 2018--- Huawei Publication Win-win magazine; [https://www.huawei.com/en/about-huawei/publications/.../sail-the-atlantic-with-camte]

[22] O-Africa, Tim Katlic, 2015 SSA Broadband Facts from 'MIS 2014' Report Only Marginally Improved This Year, [http://www.oafrica.com/broadband/ssa-broadband-facts-from-mis-2014-report-only-marginally-improved-thisyear/].

[23] Gsmamobileeconomy.Com, $2014 \quad \& \quad 2015 \quad$ Mobile Economy; e-Report; Available at [www.gsmamobileeconomy.com];

[24] Myjoyonline.com, Franklin Cudjoe, 2015 The Death of Telecoms Regulation in Ghana: Poor policy direction towards $4 G$ Licensing and LTE Evolution, [myjoyonline.com].

[25] O-Africa, Alan Knott-Craig, 2011 On MXit, 4G, Ethiopian bloggers, rural Uganda, Sudan, Broadband \& Mobile, 2011, [http://www.oafrica.com/mobile/on-mxit-4g-ethiopian-bloggers-rural-uganda-sudan/].

[26] State of the Art Mobile Internet Connectivity and its Impact on e-Commerce Note; Directorate General for Internal Policies Policy Department A: Economic And Scientific Policy; 2012; English: Parliament ISBN 978-92-823-3822, DOI10.2861/12506.

[27] BiztechAfrica, 2016 MTN Cameroon Board lauds 3G+, 4G-LTE rollouts Telecoms, Main Africa MTN Cameroon Board lauds 3G+, 4G-LTE rollouts, available at: [http://myinforms.com/en/a/24362364-mtn-cameroon-board-lauds3g-4g-lte-rollouts/]. () Biztechafrica.com.

[28] Trichy Venkataraman Krishnamurthy and Rajaneesh Shetty, 2014 4G: Deployment Strategies and Operational Implications: Managing Critical Decisions in Deployment of 4G/LTE Networks and their Effects on Network Operations and Business 2014 ${ }^{\text {th }}$ Edition; Apress; 2014 edition; ISBN-10: 1430263253, ISBN-13: 978-1430263258. 


\section{BIOGRAPHIES OF AUTHORS}
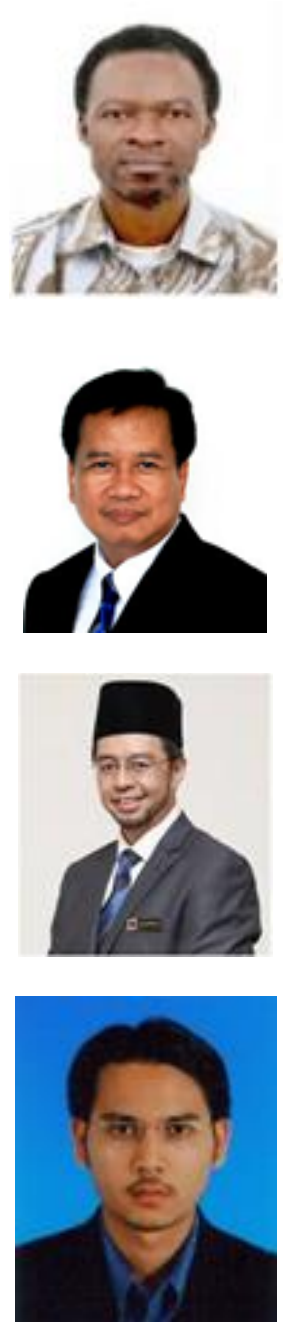

Mohamed Njikam, PhD candidate in Mobile Wireless Multimedia Networks with a MSc. Information \& Communication Technology in Wireless Networking and Internet Computing, Dept. System and Computer Communication, Faculty of ICT (FTMK), UTeM; obtained a BSc. Management Information Systems at International Islamic University Malaysia (IIUM) and a BT in Electrical Engineering (F3) / University of Yaoundé Cameroon.

Nanna Suryana Herman, PhD. in GIS, Wageningen Research University, the Netherlands, MSc. In Computer Assisted Regional Planning, Institute for Geoinformatics and Earth Observation (ITC), the Netherlands, B.Eng. Soil \& Water Engineering, UNPAD, Bandung Indonesia; Fields of specialization: System and GIS Interoperability, Spatial Data Quality Management, Spatial Modelling and Analysis, Mobile GIS. Academic Commitments: Professor in the Department of Software Engineering, Faculty of Information and Communication Technology (FTMK); Chairman of C-ACT Center of Excellence, Centre for Research and Innovation Management UTeM.

Shahrin Sahib, PhD in Parallel Processing at University of Sheffield (UK), Bachelor and Master's degree in Computer Systems Engineering at Purdue University (USA); Professor in the Department of Computer Systems and Communication and UTeM Vice-Chancellor since 2014. Academic areas of interest: Networking, Computer Systems, Network Administration and Design through working, teaching and undertaking research in those areas, Network and Computer Security.

Mohd Fairuz Iskandar Othman, PhD. Senior Lecturer, Department of Computer Systems and Communication, Faculty of Information and Communication Technology, FTMK (UTeM). He received his $\mathrm{PhD}$ in Information Technology from Queensland University of Technology and Master's degree in Internetworking from the University of Technology, Sydney. His research interests include human behavioral issues in Information Security, IT Governance and Management, and other related topics in Computer Networks and Computer Security. 